\title{
Bücherschau.
}

\section{Anleitung zur Darstellung chemischer anorganischer Präparate für}

Chemiker und Pharmazeuten, von Dr. Reinhart Blochmann, Prof. a. d. Univ. Königsberg. Leipzig 1895. Vert \& Co., Preis 2.20 Mk. 5 Bogen. 8. „Das vorliegende Büchlein soll dem Studierenden der Chemie und Pharmazie als erste Anleitung bei der Darstellung anorganischer Präparate dienen, nachdem er durch praktische Übungen auf dem Gebiete der analytischen Chemie festen Fufs gefalst hat." Diesem von dem Verf. in der Vorrede ausgesprochenen Zweek entspricht das Büchlein voliständig. Es enthält cine Answahlı einfacher Übungen auf dem Gebiete der präparativen Chemie, für den Aufänger bestimmt. Fïr die Auswahl der Präparate war malsgebend, dal's als Ausgangsmaterial häufiger vorkommende Naturprodukte (z. B. Sehwerspat, Kryolith, Grauspielsglanzerz) oder Produkte der chemischen Grolsindustrie (z. B. Sehwefels:̈̈ure, Salzsäure, Soda, Salpeter) dienen sollten, oder aber Substanzen in Anwendung kämen, die bei vorhergehenden Übungen als (zuweilen lästige) Nebenprodukte entstinden waren nnd gewonnen wurden. Ferner ist Riücksiclit bei der Auswahl genommen auf die Zeitdauer, welehe die einzelnen Operationen olne Unterbrechung erfordern. Sie übersteigt in der Regel nieht mehr als 2-3 Stunden. Endlich sollen die vorgeschricbenen präparativen Aufgaben Gelegenheit geben, die verschiedenartigsten chcmischen Vorgänge, die gebräuchlichsten Operationen und viclfach bewährte, oft angewendete und leicht zu beschaffende Apparate kennen zu lernen.

Eine besondere Sorgfalt ist der Aufarbeitung der Nebenprodukte gewidmet, so dals der Schüler gewöhnt wird, bei chemisehen Arbeiten auf den Gesamtverlauf der Reaktionen zu achten. Die entstandencu Körper werden meist wieder in sehr geschickter Weise zum Ausgangsmaterial für andere Präparate herangezogen.

Es wäre zu wünschen, dals dies Büchlein eine gröfsere Verbreitung erfahren würde, namentlich dort, wo es sich um den elementaren Unterricht von Anfüngern handelt, und es sei allen deneu, die ihn zu leiten haben, empfohlen.

Richard Loren:.

Berichtigung.

Band IX Seite 284, Zeile 3 von unten, soll heiben 4-7, anstatt 4-8. Juius THomshe. 